\title{
Yúdice, George, 2002, El recurso de la cultura. Usos de la cultura en la era global, Editorial Gedisa, Barcelona.
}

G eorge Yúdice encausa sus esfuerzos intelectuales para hacer explícita la red de significados bastante opacos y frágiles que evoca la cultura en las sociedades contemporáneas. Las ficciones del encantamiento modernizador cristalizaron alrededor de una "idea de cultura" como cemento ideológico de la sociedad que devino idea-fuerza directriz del pensamiento y de la práctica en los tiempos modernos (Bueno, 1997). En consecuencia, la cultura se ha embebido densamente de ideología $y$, en tanto un poderoso "filtro intelectual", ha modulado la comprensión del mundo y las formas de actuar en él, así como redefinido en contrahechos términos "nacionales", de "elite", "clase" o "masa".

La cultura ha sido esencial en el discurso político del estado nacional y su proyecto de operar con eficacia una clausura de sentido para integrar la "sociedad nacional" como totalidad homogénea, delimitar fronteras físicas y simbólicas, controlar, disciplinar y patrimonializar símbolos, valores y lengua legítima. Este protagonismo y los múltiples usos de la cultura a partir de apropiaciones sociopolíticas, educativas y económicas se acrecientan hoy con nuevos sentidos cuando, como dice Yúdice en esta lúcida obra que comentamos (Yúdice, 2002: 44), ${ }^{1}$ la relación entre globalización y cultura es de conveniencia porque la reproducción del sistema de relaciones capitalistas se culturaliza.

La sociedad contemporánea es una sociedad de la cultura en la medida en que la cultura se encuentra en el centro mismo de la re-producción simbólica y material de la vida social. Por tanto, el control de esta lógica cultural es un ámbito de anclaje tanto de los procesos macroeconómicos y las relaciones de poder, que sabemos son siempre de dominación, como de las preocupaciones del campo intelectual y, en consecuencia, de los análisis culturales de las múltiples dimensiones de la vida social, sociedad, las subjetividades, las prácticas y los conflictos emergentes alrededor de actualizadas formas de producción cultural, integración social y socialización de los hombres. También, de los simulacros o las simulaciones culturales de las relaciones sociales porque, según George Yúdice: "El recurso de la cultura sustenta la performatividad en cuanto lógica fundamental de la vida social hoy" (Yúdice, 2002: 43). ${ }^{2}$

Precisamente, El recurso de la cultura reúne reflexiones sustantivas en distintos niveles analíticos sobre los significativos cambios de la cultura en la actualidad y las reconfiguraciones de su relación con una sociedad cada vez menos moderna o extremamente moderna por la fuerza de los procesos emergentes en la constitución del 
tejido social y las acciones de múltiples actores como aproximaciones a los modelos imaginados (performatividad). Las nuevas determinaciones de la sociedad y la cultura contemporáneas tornan problemática las formas de entender la naturaleza del tiempo social e histórico y demandan análisis culturales plausibles de la realidad social. En ello ingresa con vigor intelectual George Yúdice al demostrar cómo la cultura ha sido elegida por el capital como fuerza constitutiva para la explotación, la acumulación y el crecimiento económico. Asíla propiedad intelectual y los derechos de autor, como formas culturales constitutivas de la sociedad del conocimiento, son una nueva mina de contenidos altamente redituables en manos de los productores $\mathrm{y}$ distribuidores.

De muchas maneras, El recurso de la cultura es una de esas obras provocativas e inquietantes intelectualmente. Tras las raíces de nuestra contemporaneidad, su autor hace un diagnóstico exhaustivo y sin solemnidades de varios usos de la cultura en la era global y, además, invita a pensar en la cultura misma más allá de su instrumentalización en la legitimación de procesos de desarrollo urbano, económico, tecnológico, la resolución de conflictos y la generación de empleo. Su crítica apunta hacia los que han pensado esta nueva era de la globalización como una tendencia a la lisa y llana homogenización cultural del mundo o mundialización cultural; cuando, más bien, se caracteriza por una "transculturalidad planetaria", la desterritorialización de los imaginarios a través de vivencias mundializadas y la sincronización del desarrollo capitalista con alcances geográficos y metas que conjeturan un orbe menos moderno sin llegar a serlo plenamente porque se radicaliza en sus dramas civilizatorios. Tampoco cede ante los que aplican esquemas o modelos interpretativos extemporáneos -sobre todo norteamericanos- para explicar las realidades latinoamericanas $y$, menos, con los que hacen loas del papel de la agencia humana y de los movimientos sociales. Sin embargo, trata de extraer lecciones de los movimientos a partir de la documentación exhaustiva de algunos casos en Estados Unidos de América (EUA) y América Latina. Su visión es más compleja, diáfana y reflexiva. Su perspectiva crítica oscila entre el análisis de los procesos fundamentales y de las coyunturas abiertas por eventos conmocionantes como los del once de septiembre de 2001.

Yúdice afirma y demuestra que la cultura como recurso económico se legitimó e impuso sobre otras interpretaciones. Ésta se ha convertido en una fuerza vital y se ha situado en el seno del proceso de producción y reproducción ampliada del valor como esencia de la sociedad capitalista (Acanda, 2002:11-20). La racionalidad económica absorbió la creación cultural al subsumir a los productos culturales en la lógica de las mercancías hasta controlar la producción de valor, “...la gestión, la conservación, el acceso, la distribución y la inversión" (Yúdice, 2002: 13), así como el propio consumo de las mercancías culturales a través de mecanismos o mediaciones que ejercen una profunda violencia simbólica para extraer la atención de los públicos - labor-. La integración de lo simbólico y lo social se reconoce en las sociedades actuales pero, como dice Eagleton, a través del reencuentro de lo simbólico-cultural y lo económico (Eagleton, 1999:37).

La cultura adquiere una importancia decisiva como concepción general para la transformación de la realidad, es decir, para los procesos de cambio. De hecho no se puede hablar de un desarrollo social real, efectivo y perdurable si éste no está dimensionado culturalmente. Yúdice advierte que la valoración del capital cultural en 
las estrategias de desarrollo durante la década de los noventa, reemplazó el énfasis durante las precedentes en los capitales físico, humano o social (Yúdice, 2002: 28). Él es un conocedor privilegiado de las estrategias culturales de los agentes económicos y de la sociedad civil que dicen promover la responsabilidad, la voluntad y el compromiso con un desarrollo con democracia, equidad y participación. También, la cultura como recurso cobra legitimidad entre los políticos que deciden la inversión y protección culturales por su valor utilitario para disminuir los conflictos, procurar justicia social e impulsar el desarrollo económico y, de esta manera, para fortalecer la sociedad civil como soporte del desarrollo del capital, promover el desarrollo del turismo, de las industrias culturales en general y de todas las que dependen de la propiedad intelectual.

Tal dinámica ha resultado bien compleja en la sociedad de flujos globales de bienes materiales y simbólicos, de fuerza de trabajo manual e intelectual, porque la lógica cultural planetaria dinamita la unidad de las sociedades nacionales al multiplicarse las identidades locales o supranacionales. Esta cultura traslaticia, su transformación global y valor instrumental, se rige por una nueva lógica de acumulación del capital pautada por la administración e inversión transnacional en las industrias culturales, la propiedad intelectual y los derechos de autor. La transterritorialidad de la cultura resultante complica la cuestión de la soberanía nacional. La emergencia de fenómenos sociales alusivos de cambios epocales se ha expresado en complejas dinámicas espaciales y de articulación de escalas en los procesos de estructuración de las relaciones sociales y de la acción humana. Al respecto la fuerza de este texto es inusitada porque ataca las hipótesis territorializadas en la sociedad nacional de los estudios clásicos de la cultura desde las perspectivas antropológica, histórica y sociológica. Asimismo, articula análisis de los procesos socioculturales en diferentes escalas para comprender la lógica transterritorial al pasar de fenómenos particulares como los del mundo funk carioca, la producción cultural en la frontera común de México y EUA o los neozapatistas en Chiapas, a sus locus: las ciudades - como Río de Janeiro, Miami o Bilbao-, las maquilas culturales, las culturas autóctonas, la selva Lacandona y la sociedad civil, los movimientos sociales o las ONG. Todos integrados en una lógica global regida por la hiperinflación de símbolos, el capitalismo de consumo, el libre comercio y la mediación palmaria de las corporaciones transnacionales. Con ello se apunta a vislumbrar el papel de la cultura en la construcción de un tipo de ciudadanía global en tiempos de crisis e incertidumbre de los lazos sociales.

Sin duda, la historia hizo justicia a los representantes del pensamiento crítico, cuando advirtieron con agudeza que "la cultura" perdía autonomía incorporada al engranaje económicoadministrativo. Ello se acentúa en la medida en que se conforman conglomerados multimedias como parte del proceso globalizador de la cultura y de las políticas de privatizaciones de las empresas públicas. Éstos expanden e internacionalizan los servicios de producción como parte del nuevo modelo posfordista organizado a través de esta lógica placentaria y preocupado por la máxima utilidad en el mercado mundial. Por ejemplo, la industria del cine, del audiovisual en general, obtiene jugosos dividendos a partir de la especialización flexible que permite diferenciar los modos de producción, segmentar los mercados de consumo cultural, fijando 
nociones de proximidad y distancia cultural, narrativas de identidad, formas de conocimiento transculturales.

La definición de los rasgos histórico-culturales, distintivos de la modernidad tardía, pasa por el desarrollo de tecnologías mediáticas que construyen una "cultura" que asegura, como fuerza dominante de socialización, cierta variada uniformidad de elección y, al mismo tiempo, nuevas formas de vigilancia y control sociales. Hoy la trama envolvente del mundo es mediática, como diría Baudrillard, y a través de ella se difunden los procesos simbólicos, se reproducen artefactos, necesidades y consumidores cuyas experiencias y subjetividades se diluyen en la mayor opacidad de la realidad social; al mismo tiempo, esa trama contribuye a la rutinización acelerada de lo nuevo teniendo en cuenta que casi toda la producción cultural se realiza bajo el amparo de la forma filistea de la mercancía. Ahora se incrementa la demanda social de bienes culturales, se asienta el hedonismo como modo de vida impulsado por el sistema de ventas $\mathrm{y}$, además, se desarrollan políticas públicas para satisfacer estos correlatos de los cambios globalizadores.

Paradójicamente, los estados latinoamericanos bajo las perversiones de las políticas neoliberales han reducido durante las últimas décadas el gasto en servicios sociales $y$, fundamentalmente, en el financiamiento de programas educativos y culturales, así como la inversión en investigación científica; y, sobre todo, son notables sus debilidades para regular las transformaciones económicas que caracterizan a la actual división internacional del trabajo cultural (Wortman, 2001: 251-267). ${ }^{3}$ Razón tiene Yúdice al seguir el proceso político cultural de construcción de la sociedad neoliberal a partir de políticas para privatizar, reducir y descentralizar el sector público en lo tocante a la cultura, y constatar cómo se ha desvirtuado la discusión sobre la soberanía cultural ante la reducción del carácter nacional de las producciones estéticas o, para decirlo de otra manera, ante el paso del "made" al "assembled" o al "imported by". Antes, la cuestión de orden era proteger e impulsar una producción endógena de bienes de consumo cultural que permitiera cuotas de programación complementarias para las importaciones; ahora, las tendencias nacionalistas de protección transitan a ser regionales o continentales.

Yúdice advierte el impulso de discusiones sobre el papel de las culturas regionales frente a la inminente ruina de las industrias culturales nacionales, la reorganización mercantil del intercambio de bienes culturales en función de reconsiderar sus beneficios arancelarios e impositivos - como en el caso de los libros-, y el desequilibrio comercial por el desmesurado poder audiovisual de EUA, que monopoliza la producción, distribución y programación en las redes y en los sistemas satelitales o de cable tanto latinoamericanos como europeos. De manera tal que la integración del continente se está llevando a cabo en los términos estipulados por la industria norteamericana de la comunicación - no exenta de relaciones con la militar-, es decir, a expensas de los países latinoamericanos y favoreciendo el "bombardeo cultural", la "americanización" o "americanidad" de tejidos sociales si no desechos, sí deteriorados y fragmentados culturalmente. Esta situación actualiza la necesidad de ensayar políticas innovadoras para regular los mercados regionales de bienes culturales y de sistemas más eficaces de intermediación cultural no sólo en la producción, la circulación y el consumo, sino en el aprendizaje de las interrelaciones culturales. ${ }^{4}$ 
Una de las contribuciones más significativas de este libro consiste en revelar esa estructura de la Nueva División Internacional de los sistemas de producción y consumo de objetos y prácticas culturales. La localización, circulación y consumo de bienes simbólicos desmaterializados, y la concentración de sus dividendos, como fuentes de crecimiento económico, alcanzan volúmenes inusitados en el comercio mundial. George Yúdice afirma que las industrias del entretenimiento y de los derechos de autor -música, filmes, vídeos, revistas y televisión- son las que más aportan al producto interno bruto de EUA. ${ }^{5}$ Los trabajadores culturales se han convertido en mineros que excavan en las profundidades de las minas de las culturas en tanto reservas disponibles en cuanto proveedoras de contenidos sobre los que no se tiene más derecho que el fijado en contratos dilapidarios y leyes injustas que favorecen a las corporaciones. En este sentido, la cultura devine en un recurso manipulado extensa e intensivamente en el escenario del siglo XXI.

Sin embargo, la cuestión del uso y apropiación de los productos culturales ha provocado encendidas discusiones en los foros internacionales en torno a su valor mercantil o cultural, su significado para la economía o las identidades, sobre el reconocimiento de la diversidad cultural, de las necesidades reales de las comunidades diferentes, es decir, sobre la participación democrática, los derechos de ciudadanía política, civil, social y, sobre todo, cultural. Por ello, Yúdice argumenta que ante el tráfico acelerado de cultura como recurso por la globalización, instituciones globales como el Banco Mundial, el Banco Interamericano de Desarrollo y numerosas fundaciones han comenzado a invertir en la cultura como esfera económica de creciente importancia. De hecho, la circulación de las riquezas desmaterializadas es (des)regulada o liberalizada según el Acuerdo General sobre Aranceles Aduaneros y Comercio y, su émula, la Organización Mundial del Comercio. Estas tratan de gerenciar la nueva división del trabajo cultural basada en la brecha entre la inversión y administración transnacional y el llamado a las diferencias nacionales o locales dentro de los circuitos globales (Yúdice, 2002: 291). ${ }^{6}$

En general, la tendencia ha sido apostar por la gestión del patrimonio, la administración y el uso sustentable de los recursos, conocimientos, tecnologías y de sus riesgos. La gerencialidad de la cultura es la encargada de localizar los intercambios materiales y simbólicos más allá de la institucionalización del discurso. Así, el modelo empresarial de la dinámica económica del capitalismo tardío que rige la lógica social se impuso en los campos de producción de conocimientos como una intermediación cultural. Ello se constata en las industrias del copyright_-del libro, la música, la prensa, la TV-, en los procesos de comunicación masiva que es donde se desenvuelven las principales actividades culturales relativas tanto a la presentación de los productos y la constitución de sus públicos consumidores - marketing y publicidad-, como a las formas de producción mismas. Las industrias culturales tienen y tendrán un papel fundamental en la dinámica de la económica cultural basada en un nuevo paradigma tecnológico, los cambios en los vínculos socioculturales y las demandas de las sociedades contemporáneas. Al respecto Yúdice hace una crítica radical: la economía cultural no deja de ser política en la medida en que la globalización neoliberal ha redefinido la conveniencia, adecuación o pertinencia del “imperialismo cultural” de Occidente (Yúdice, 
2002: 44-45). Afirma que estas industrias se han convertido en un espacio significativo de disputa en la articulación de cultura, ideología y política, porque en la actualidad no es tanto en la producción de sentido sino en su circulación donde se juegan proyectos políticos: “...en la circulación, mucho más que en la producción, la cultura deviene política" (Hopenhayn, 2001: 69-89).

Esta economía política y cultural apoyada en el desarrollo de nuevas tecnologías y el procesamiento de información, favorece el protagonismo mediático, en cuanto articuladores sociales, en la constitución y el ejercicio de una ciudadanía regulada por la fuerza estética de la imagen. También, en su anverso: refuerza las grandes asimetrías de poder simbólico y los retrocesos en lo social, en la calidad de la vida cívica y política. Entonces, la cultura es un terreno resbaladizo de negociación de los cambios acelerados de la sociedad capitalista; de ninguna manera deja de ser un terreno de lucha a pesar de que su reconversión neoliberal sugiera otra cosa. Los campos de producción cultural se reconfiguran a partir de un conjunto de políticas, prácticas y discursos que operan, como otras estrategias gubernamentales, para gerenciar, disciplinar y reculturizar a poblaciones cuyas diferencias sociales son administradas o reguladas alrededor del eje mercado por las principales instancias o medios y corporaciones transnacionales (Yúdice, 2002: 39).

Por ello, es capital discutir sobre el papel de las políticas culturales y la contribución de los intelectuales. Sin duda, la plausibilidad de las políticas culturales presupone un análisis cultural de la sociedad. Pensar en la pertinencia de las políticas culturales a partir de las transformaciones actuales y potenciales de las relaciones sociales, implica aclarar más los vínculos de las políticas con los presupuestos y efectos del modelo neoliberal, el modo que la globalización cultural ha adoptado en cada territorio - producción, distribución, circulación y consumo cultural-, así como las formas institucionales que asume la hegemonía y la resistencia cultural. Yúdice lo patentiza en las palabras de un shuar de Ecuador a connotados museólogos conservacionistas: “...lo que en rigor se necesita es documentar la cultura para el desarrollo cultural de la comunidad" (Yúdice, 2002: 130).

Los estudios culturales podrían dar cuenta de cómo las políticas culturales modulan y constituyen el proceso social de (re)producción y distribución desigual de bienes y servicios culturales; cómo éstas responden al reto que plantea la sociedad moderna de cohesión y consenso social alrededor de renovados valores sociales y de producir sujetos o ciudadanos ideales - productivos, éticos, responsables-. Desde un plano más teórico, se puede entender las políticas culturales como vehículos de producción y difusión de formas de saber, códigos de representación y procesos de apropiación y definición de la realidad. Las políticas culturales pueden ser, entonces, como fuerzas moduladoras de las sinergias de la labor o el trabajo cultural, como médulas de la cultura - para Yúdice-, que contribuyen a la creación de una realidad acorde con los intereses de una colectividad y a fijar pautas equitativas o justas de distribución y acceso a los bienes y servicios culturales. Por ello, pueden entenderse como procesos sociales de distribución de poder a través de un conjunto de estrategias o líneas de actuación de grupos de trabajadores de la cultura, instituciones y agentes entre los que no puede soslayarse el Estado. Argumentar sus interrelaciones y las brechas entre el deber ser y lo que realmente se hace en la práctica, es el imperativo de los estudios culturales empeñados en debatir el significado de la cultura. 
Alain Basail Rodríguez

A través de las páginas de El recurso de la cultura, el lector desentrañará la actualidad de la agenda planteada por George Yúdice, sus implicaciones para los debates contemporáneos sobre el "poder cultural". Fundamentalmente, encontrará claves para pensar los mundos de la cultura, la política y la economía, sus intermediaciones y posibilidades de regulación o emancipación (Yúdice, 2002: 40). En particular, sobre los estudios culturales críticos en un diálogo fecundo entre la tradición anglonorteamericana y latinoamericana representada, esta última, por Renato Ortiz, Jesús Martín-Barbero, Néstor García Canclini, Daniel Mato, José Manuel Valenzuela y otros; la intrincada relación entre la cultura y los fines-medios del desarrollo; el papel de los agentes o sectores que (no) han apostado por la cultura como el Estado, la iniciativa privada, las fundaciones, ONG, comunidades y familias, así como su dependencia recíproca o complementariedad sinérgica; el debate centralización-descentralización; el acercamiento entre cultura y comunidad; el imperativo de democratización, participación, inclusión e intercambio ć́vico virtuoso de actores locales y regionales que demandan ser actores culturales; el continum público-privado; la vitalidad de las formas de sociabilidad locales, el asociacionismo, la solidaridad; así como la relación consumo-ciudadanía-derechos sociales, políticos, civiles y culturales desde una perspectiva ética, democráticamente incluyente y una práctica reflexiva.

Esta obra es sumamente pertinente en momentos en los que la discusión sobre el protagonismo y los imperativos de la cultura en la actual etapa de reestructuración mundial están siendo un terreno de confrontación entre intelectuales con visiones de lo social/humano y compromisos políticos encontrados. Yúdice tiene una visión crítica de las formas en que se viene dando la mundialización y desembala una respuesta sumamente autorizada a aquellos para los que el discurso sobre la cultura adquiere, a veces, cínicas connotaciones de moda efímera y de una pose política ad hoc-neoconservadorafomentada por los debates sobre el ethos epocal.

El recurso de la cultura en manos de un lector interesado en los vínculos entre cultura, política, sociedad y cambio social, contribuirá a la comprensión de las implicaciones socioculturales de las políticas y los proyectos de desarrollo, a su legitimación como estrategias de inversión en lo social, a la sensibilización de los planificadores sobre la importancia de la cultura como un proceso social creativo $y$, por último, a perfilar las interpretaciones sobre el dinamismo de los campos de producción cultural y sus mecanismos para la promoción de innovaciones como motores del crecimiento económico. Sobre todo, será un referente obligado en la discusión sobre el papel de las políticas culturales y de la agencia humana en la constitución y la dinámica cultural de la sociedad contemporánea.

\section{Notas}

${ }^{1}$ George Yúdice, El recurso de la cultura. Usos de la cultura en la era global, Editorial Gedisa, Barcelona, p. 44.

${ }^{2}$ Idem., p. 43.

${ }^{3}$ Ana Wortman, 2001, "El desafío de las políticas culturales en la Argentina”, p.254. en Daniel Mato (coord.), Cultura y transformaciones sociales en tiempos de globalización 2, CLACSOASDI, Venezuela, pp.251-267.

${ }^{4}$ Por ejemplo, analiza la dimensión cultural del NAFTA/ TLCAN y el MERCOSUR. Véase Capítulo 8.

${ }^{5}$ Véase además, Toby Miller y George Yúdice, Politica Cultural, Editorial Gedisa, Barcelona, 2004.

${ }^{6}$ George Yúdice, Op. cit., p. 291.

Alain Basail Rodríguez CESMECA-UNICACH 